\title{
Decision-making in the critically ill neonate: cultural background $v$ individual life experiences
}

\author{
Cathy Hammerman, Eti Kornbluth, Ofer Lavie, Pnina Zadka, Yeshayahu Aboulafia \\ and Arthur I Eidelman Shaare Zedek Medical Center, Hebrew University - Hadassah Medical School and \\ Central Bureau of Statistics, ferusalem, Israel
}

\begin{abstract}
Objectives-In treating critically ill neonates, situations occasionally arise in which aggressive medical treatment prolongs the inevitable death rather than prolonging life. Decisions as to limitation of neonatal medical intervention remain controversial and the primary responsibility of the generally unprepared family. This research was designed to study response patterns of expectant mothers towards treatment of critically ill and/or malformed infants.

Design/setting-Attitudes were studied via comprehensive questionnaires divided into three sections: 1-Sociodemographic data and prior personal experience with perinatal problems; 2-Theoretical philosophical principles used in making medical ethical decisions; and 3-Hypothetical case scenarios with choices of treatment options.

Subjects and results-Six hundred and fifty pregnant women were studied. Maternal birthplace $(p=0.005)$ and level of religious observance $(p=0 \cdot 02)$ were strongly associated with the desire for maximally aggressive medical intervention in the hypothetical case scenario. Specific personal experiences such as infertility problems, previous children with serious mental or physical problems were not correlated with the selection of different treatment choices. Of the theoretical principles studied, only the desire to preserve life at all costs was significantly associated with the choice for maximal medical treatment $(p=0.003)$.

Conclusions-Maternal ethnocultural background and philosophical principles more profoundly influenced medical ethical decision-making than did specific personal life experiences.
\end{abstract}

With the increased survival of ever smaller premature infants and the salvage of previously nonviable malformed or critically ill infants, many moral and ethical dilemmas have intensified. What happens when the best of medical intervention can be expected to result in the survival of a severely

\section{Key words}

Critically ill neonates; malformed infants; medical ethics; Down's syndrome; cultural background. handicapped child at the cost of an enormous emotional and financial burden to the family? How aggressive should we be when the chances of survival itself, despite intensive medical care, are minimal? Clearly there are situations in which continued medical treatment essentially prolongs the inevitable death process rather than prolonging life. Yet the specifics of when and how to set limits on medical intervention remain complex and controversial.

It is crucial that the family be involved in medical ethical decision-making. However, in caring for neonates, we most often must deal with situations in which a severely ill or malformed infant is thrust unexpectedly upon a family still struggling with the emotional stress and turmoil of the post partum period and with no previous relationship with the neonatal staff. Yet critical life and death decisions must be made.

The American Academy of Pediatrics, in its guidelines on forgoing life-sustaining medical treatment ${ }^{1}$ states that [respect for] "autonomy accepts the likelihood that different persons may judge benefits differently". Although specific emotional needs will surely vary, we hypothesised that there would be patterns to parental reactions towards medical ethical problem-solving. We sought, therefore, to survey the attitudes of pregnant women and to attempt to deduce patterns of parental response. It is hoped that increasing staff awareness of these patterns will lead to more effective and sensitive communication with the families during times of overwhelming stress.

\section{Methods}

Attitudes towards medical ethical decision-making were studied via comprehensive questionnaires which were original, devised from the joint input of a neonatologist, a social worker and an obstetrician.

\section{SUBJECTS}

Pregnant women (during the 2 nd or 3 rd trimester) were targeted for study. They were approached during routine visits to either the prenatal or the infertility clinics of the Shaare Zedek Medical 
Center, a university-affiliated teaching hospital. A volunteer spoke briefly with the woman, explaining the purpose of the study and assuring her of anonymity before distributing the questionnaire.

In order to minimise potential technical difficulties, questions were either multiple choice, yes/no or called for one to two-word factual answers. None of the questions were open-ended. Questionnaires were available in four different languages and each mother was able to choose that with which she felt most comfortable. The questionnaires were divided into three sections: 1. Sociodemographic data including age, religion, level of religious observance and parity. Also included were questions about prior experience with infertility, prematurity and/or infants suffering from physical or mental disabilities. 2. Respondents were asked to rate the importance of certain factors which they might use to assist them in making medical ethical decisions. These factors included preserving life at all costs, prognosis for future productivity and need to avoid physical pain or suffering. 3. Respondents were then presented with six hypothetical case scenarios including Down's syndrome, extreme prematurity, severe perinatal asphyxia, cleft palate, Trisomy 18 and congenital heart disease. Case studies were described in great detail, in nontechnical language to prevent misunderstandings of either the factual aspects of the cases or the implications thereof. Each case was followed by three possible treatment options: maximal medical treatment (resuscitation and ventilatory assistance as needed), moderate medical treatment (up to, but not including resuscitation and ventilator) or minimal medical treatment (feeding/ warmth).

\section{ANALYSIS OF DATA}

Factors which potentially affected decision-making were first analyzed as categorical variables by $\mathrm{Chi}$ Square analysis to examine for independence between variables of interest and clinical decision options. Specifically, maternal age was categorised by decade; level of religious observance as ultraorthodox/fundamentalist, orthodox, traditional or secular; parity as primipara, multipara (para 2-5) or grandmultipara (para $6+$ ); education as primary, high school or university; and profession was ranked on a scale ranging from 1 which represented skilled professionals, to 6 which referred to unskilled workers. The scale is fully described elsewhere. ${ }^{2}$

Responses to the theoretical principles felt to be important in making medical ethical decisions, included preserving life at all costs, prognosis for future productivity and need to avoid physical suffering were categorised as mildly important, moderately important and extremely important. Responses to hypothetical case histories were categorised as maximal medical treatment, moderate medical treatment without resuscitation or assisted ventilation or minimal medical treatment (provision of feeding and warmth).
Multivariate analysis was then performed using a multiple logistic regression model. All continuous variables, for example age, were entered as continuous. Others were entered into the model as categorical variables. Odds ratios and $95 \%$ confidence intervals were calculated and used to estimate the relative contribution of the variables to decisionmaking. Spearman rank correlations were used to define correlations between variables.

\section{Results}

STUDY SUBJECTS

Six hundred and fifty respondents completed the questionnaires, of whom 88 were from the infertility clinic and the remainder from the routine prenatal clinic. Sociodemographic data describing the entire study population are provided in the lefthand column of table 1 . They show that most of our mothers were Israeli-born multiparas in their 20s and 30s, who had completed at least a high school education. Twenty-seven per cent of our mothers were housewives. The distribution of the professions of the remainder of the population within the 1-6 scale is presented in table 1 . Fifteen per cent of the respondents were Moslem; the remainder were predominantly Jewish. The distribution of maternal countries of origin within our study population is similar to the comparable distribution country-wide among women in the child-bearing age range. ${ }^{3}$

\section{INFLUENCE OF SOCIODEMOGRAPHIC VARIABLES}

Down's syndrome was selected as a representative case scenario because it was felt to have broad recognition within the community and to be of sufficient severity to justify consideration of the various options, while, at the same time, not to be incompatible with life. The distribution of the various sociodemographic factors among those respondents desiring maximal $\mathrm{v}$ minimal treatment for Down's syndrome is also presented in table 1 (two righthand columns) and compared with their respective distribution in the total population. Maternal age, parity, education and level on the professional scale were equally distributed amongst all the groups.

By univariate analysis, the level of religious observance, regardless of which religion, was found significantly to impact upon medical ethical decision-making. Mothers who described themselves as ultraorthodox/ fundamentalist constituted a higher proportion of those selecting maximally aggressive medical intervention $(25 \% \mathrm{v} 17 \%$ of the total population; $\mathrm{p}<0.01)$. Conversely, mothers who described themselves as secular were proportionately more represented among those selecting minimal intervention $(31 \% \mathrm{v} 20 \%$ of the general population; $p<0 \cdot 01)$. Maternal country of origin also influenced responses. Mothers born in what was the USSR were much more likely to select minimal intervention, constituting $13 \%$ of those 
Table 1: Comparative distribution of sociodemographic characteristics among total population and those desiring maximal and minimal medical intervention in response to hypothetical Down's syndrome scenario

\begin{tabular}{|c|c|c|c|}
\hline Variable & Total population & $\begin{array}{l}\% \text { of those desiring maximal } \\
\text { intervention for Down's syndrome }\end{array}$ & $\begin{array}{l}\% \text { of those desiring minimal } \\
\text { intervention for Down's syndrome }\end{array}$ \\
\hline \multicolumn{4}{|l|}{ Age } \\
\hline$<20$ & 2 & 2 & 1 \\
\hline $20-29$ & 1 & 52 & 55 \\
\hline $30-39$ & 43 & 42 & 40 \\
\hline$\geqslant 40$ & 4 & 4 & 3 \\
\hline \multicolumn{4}{|l|}{ Education } \\
\hline Primary & 3 & 10 & 10 \\
\hline Vocational & 10 & 9 & 11 \\
\hline HS & 47 & 46 & 43 \\
\hline University & 40 & 35 & 36 \\
\hline \multicolumn{4}{|l|}{ Parity } \\
\hline Primipara & 28 & 27 & 31 \\
\hline Multipara (para 2-5) & 64 & 64 & 65 \\
\hline Grandmultipara (para 6+) & 8 & 9 & 3 \\
\hline \multicolumn{4}{|l|}{ Religious observance } \\
\hline Ultraorthodox/Fundamentalist & $17 \star \star \star$ & 25 & $8^{\star \star \star}$ \\
\hline Orthodox & $31^{\star}$ & 42 & $26^{\star \star \star}$ \\
\hline Traditional & $32^{\star}$ & 18 & $35^{\star \star \star}$ \\
\hline Secular & $20^{\star \star}$ & 16 & $31^{\star \star \star}$ \\
\hline \multicolumn{4}{|l|}{ Origin } \\
\hline Israel & 77 & 77 & 77 \\
\hline W European & 3 & 4 & 2 \\
\hline USSR & $5 t^{\star \star}$ & 1 & $13 \star \star \star$ \\
\hline North African & 7 & 8 & 3 \\
\hline American & 8 & 10 & 5 \\
\hline \multicolumn{4}{|l|}{ Profession } \\
\hline 1 & 27 & 24 & 29 \\
\hline 2 & 40 & 44 & 33 \\
\hline 3 & 15 & 17 & 11 \\
\hline 4 & 1 & 1 & 1 \\
\hline 5 & 2 & 2 & 5 \\
\hline 6 & 14 & 12 & 21 \\
\hline
\end{tabular}

${ }^{\star} \mathrm{p}<0.01$ for total population $\mathrm{v}$ maximal care; ${ }^{\star \star} \mathrm{p}<0.01$ for total population $\mathrm{v}$ minimal care; ${ }^{\star \star \star} \mathrm{p}<0.01$ for maximal $\mathrm{v}$ minimal care; $t \mathrm{p}<0.02$ for total population $\mathrm{v}$ maximal care.

desiring minimal intervention as compared with $5 \%$ of the general population $(\mathrm{p}<0 \cdot 01)$.

When the sociodemographic data were reanalyzed by a multivariate logistic regression model, both maternal birthplace in the USSR and level of religious observance remained significant determinants. The odds ratio for requesting maximal intervention for mothers born in the USSR as compared with mothers born in Israel was 0.49 (CI $0.27,0.80$; $\mathrm{p}=0.005$ ); and was 0.53 (CI $0.78,0.98 ; \mathrm{p}=0.02$ ) for mothers who described themselves as being secular as compared with ultraorthodox/fundamentalists and orthodox (figure 1).

Other factors which were analyzed and were found not to affect decision-making included prior infertility problems, a previous premature baby, and/or having had a child with brain damage or severe physical disability.

\section{DIVERSE CASE SCENARIOS}

The proportion of respondents desiring maximal intervention varied with the specifics of the case scenario. While $80 \%$ of the total population selected maximal treatment with full resuscitation in response to cases of congenital heart disease and cleft lip, $60 \%$ did so in cases of Down's syndrome, and only $43 \%$ in Trisomy 18. Nevertheless, the tendency towards selecting a maximal level of treatment was correlated across cases (by Spearman rank correlation).

\section{THEORETICAL PRINCIPLES}

Figure 2 presents the responses to a series of philosophical considerations which the respondents were asked to rate as to importance in influencing their medical ethical decision-making. In the logistic regression analysis, only the desire to preserve life at all costs significantly influenced $(p=0.003)$ the choice for maximal medical treatment in the hypothetical case scenario.

\section{WHO DECIDES?}

The great majority of respondents felt that both the parents $(89 \%)$ and the physicians $(94 \%)$ should be $N$ involved in medical ethical decision-making. Thirty N four per cent also felt it extremely important that a N religious authority be involved in making such deci- $\omega$ sions. Only $10 \%$ of our respondents felt that an ethics committee should be involved.

\section{Discussion}

With the many technological conquests of modern $\mathbb{D}$ intensive care medicine, we at times find ourselves at $\stackrel{?}{\mathbb{D}}$ risk of losing perspective of the balance between the $\varrho$ commitment to preserve human life and the equally important medical philosophical dictate of non-8 maleficence. Frequently the question shifts from? "Can we salvage this infant?" to "Should we beô. doing everything possible to salvage this infant?" 
Figure 1: Influence of sociodemographic factors on desire for maximal intervention

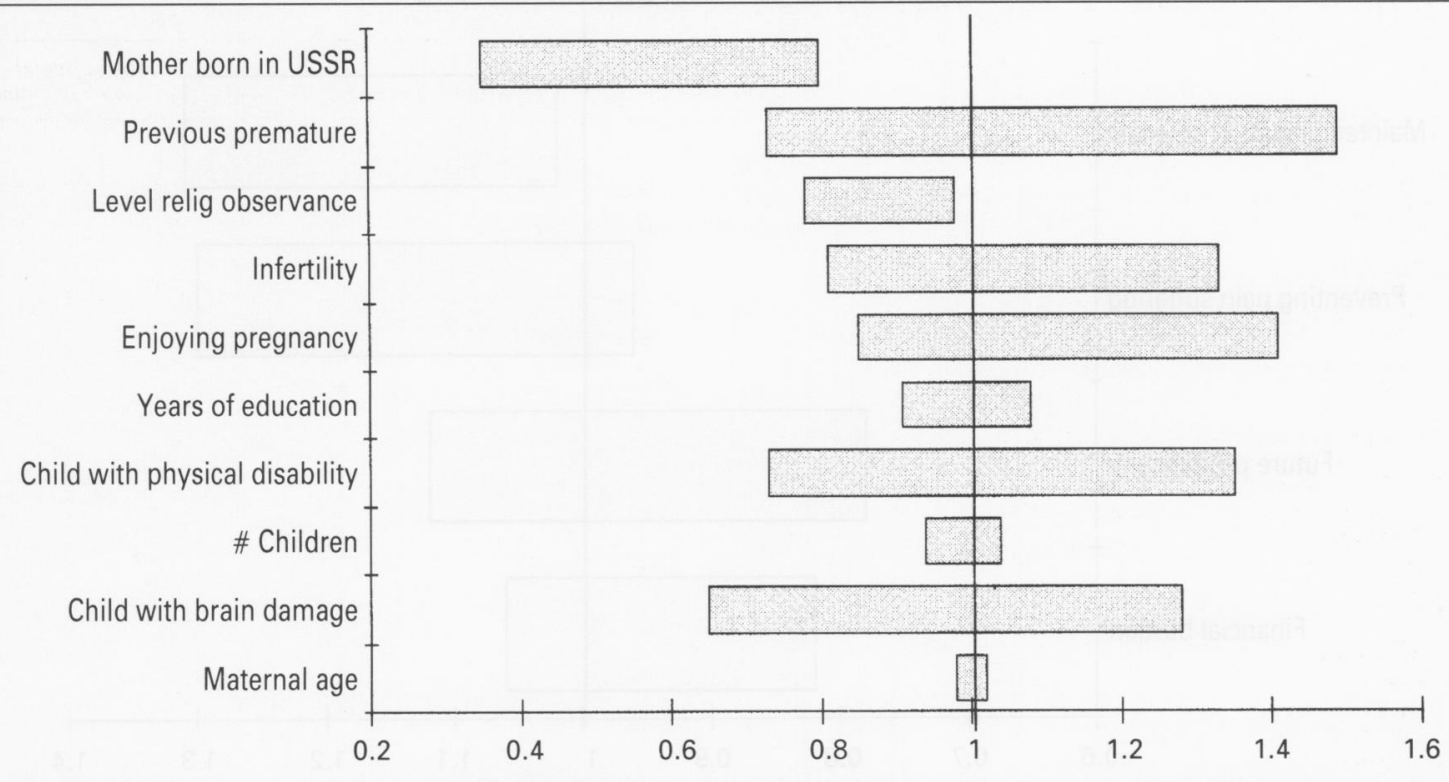

Using the hypothetical Down's syndrome scenario, confidence intervals were calculated for the various sociodemographic factors by multivariate logistic regression. Level of religious observance and maternal birthplace in the USSR were significantly correlated with the desire for maximal medical intervention.

Since infants are not capable of making decisions for themselves, ethical dilemmas concerning the nature, extent and duration of care for imperilled neonates become the primary responsibility of the often unprepared family. The American Academy of Pediatrics, in its guidelines on forgoing life-sustaining medical treatment ${ }^{1}$ states that "society generally presumes that parents should exercise the right to refuse medical treatment when nonautonomous children cannot do so for themselves".

These choices are always difficult. Parents in such situations are emotionally vulnerable, still reeling from the shock of not having the normal, healthy baby they had heretofore envisaged. They must struggle with many conflicting emotions. On the one hand there is the love, concern and hope for their baby's wellbeing counterbalanced by the grief, disappointment and guilt over the reality of their imperfect infant. They may be afraid of losing the baby while, at the same time, be terrified of the impact his/her possible survival will have on their wellbeing as a family and fearful that they will not be able to care for him/her adequately. . $^{2}$

Given the prognostic uncertainties and the emotional conflicts involved, there is unlikely to be any uniform approach to dealing with these ethical dilemmas. We in Israel are exposed to a multicultural, multiethnic society composed of people from divergent national and religious backgrounds. We hypothesised that these diverse ethnocultural backgrounds would influence attitudes towards medical ethical decision-making in our mothers. Specific emotional needs will clearly vary from family to family, however our data do indicate that cultural background may have more influence on such decision-making than individual life experiences.

Several surveys concerning attitudes towards ethical decision-making of medical staff have been published over the last few years ${ }^{567}$; however, we are aware of no other study surveying the attitudes of expectant mothers towards critically ill neonates. While questionnaire-based studies are unable, by their nature, accurately to portray the emotional turmoil of an acute clinical trauma they do provide a reasonable simulation and perhaps allow time for more carefully considered responses. From the distribution of responses to our various hypothetical cases, with the most aggressive therapies being offered to the cleft palate scenario and the least aggressive to Trisomy 18 , we deduce that our case descriptions were well understood by the respondents. This implies that the lay public is capable of understanding the essential facts concerning complicated, critical medical situations and the ramifications thereof, provided these are explained carefully and in simple language. Our questionnaire was administered specifically to pregnant women because, although they might be dealing with the same theoretical issues as others, pregnant women would provide more thoughtful and truthful responses precisely because they would be handling these issues in the context of a directly applicable practical construct.

Our study is distinguished also by the multiethnic diversity of our population, which enabled us to 
Figure 2: Influence of theoretical considerations on desire for maximal intervention

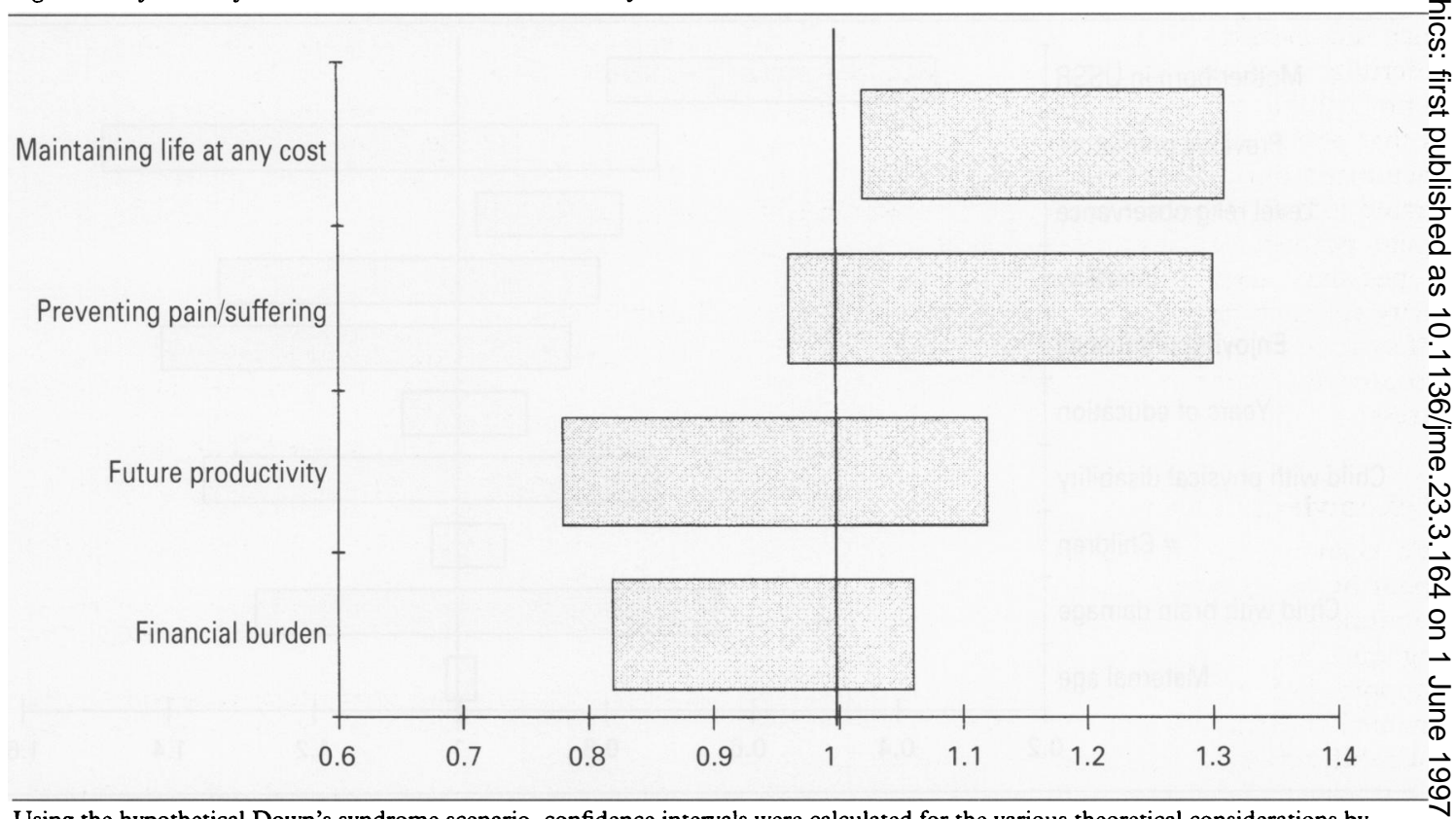

Using the hypothetical Down's syndrome scenario, confidence intervals were calculated for the various theoretical considerations by multivariate logistic regression. Only the desire to maintain life at all cost was significantly correlated with the desire for maximal medical intervention.

survey the influence of the various cultural backgrounds on critical decision-making. Finally, our questionnaire dealt with damaged neonates. Newborns present a unique ethical challenge. ${ }^{8}$ There are those who feel that it is easier to choose to forgo lifesustaining treatment in a fetus or neonate because a longstanding psychological bond with the baby has not yet been established; because infants have no autonomous decision-making capacity and because they cannot yet resist or express their desires. These distinctions are probably used subliminally by many to render it morally justifiable to make differential medical ethical treatment decisions when considering newborns. In the current study we sought to understand better our parents' wishes. In this effort, we have combined cases of congenitally malformed infants with severe acquired critical illness because, although the aetiology may be different, the resulting long-term disabilities and their effects on subsequent family dynamics are quite similar.

Two major factors influenced the desire for maximal medical intervention in our study. First the degree of religious observance. Fundamental beliefs of the more religious elements of society, regardless of which religion, tend towards an approach in which sanctity of life, rather than quality of life becomes the prime determinant. ${ }^{9}$ While the secular mother may try to balance the burden of caring for a defective, chronically dependent child who may never be able to interact normally with his/her environment, against the joy that such a life might bring, the religious mother tends to be more concerned with preserving life itself than with the quality of that life. As one of our more eloquent, ultraortho-o dox mothers responded: "Even the most severelyo handicapped child has a soul and all care must be taken to ensure his survival. In fact, I have heard that $\overrightarrow{\overrightarrow{0}}$ 'special' children have the loftiest souls. ..". This guiding principle was true amongst both our Jewish and Moslem respondents, and appears likely to be a universal phenomenon, applicable to other societies as well. Traditional religious belief is that the oppor- - i tunity to heal is a God-mandated right, and thus physicians are merely acting as representatives of God in the healing process. In this context, clergy or? other "holy men" who may more directly represento Divine wishes have the authority to override the physicians' recommendations. ${ }^{10}$

The second factor which influenced decision making was maternal country of origin - specifically, $N$ immigrant mothers born in the USSR, were muchn less aggressive in their approach to treating criticallyn ill, damaged neonates, probably reflecting prevalent attitudes in a country where families are generally limited to one to two children and where abortion ise considered an acceptable method of contraception. It is estimated ${ }^{11}$ that approximately $10 \%$ of $\mathrm{USSR}_{\square}^{-}$ women have an abortion during their childbearingo years. It is the natural evolution of this constellation of factors that may predispose these mothers to allow命 nature to follow its course when children are born faro from perfect.

In conclusion, we find it of interest to note thato the mother's philosophical principles and globat experiences, such as ethnocultural background ando. level of religious observance, had a more profound 
influence on her medical ethical decision-making than did specific past personal experiences, such as infertility problems and/or previous children with serious physical or mental disability. The implication is that philosophical and religious precepts strongly inculcated during childhood become so fully integrated into the personality that they supersede even quite powerful subsequent life experiences. It is hoped that increasing staff awareness of, and sensitivity to, such response patterns will lead to more effective and sensitive communication with various groups of parents at times of overwhelming stress.

\section{Acknowledgements}

We acknowledge with gratitude the many hours spent by our devoted nurses and volunteers in distributing and collecting questionnaires and answering questions relating to them; and the generous support of $\mathrm{Mr}$ and Mrs Stephen Hammerman which enabled the translation of the questionnaires into four different languages. We also acknowledge that the research was supported in part by the Joyce and Sidney Gamburg Neonatal Research Fund.

\section{Editor's note}

This paper was presented in part at the Society for Pediatric Research, Seattle, Washington, in May 1994.

Cathy Hammerman, $M D$, is Senior Neonatalogist at the Shaare Zedek Medical Centre, Ferusalem, Israel and Director of Research in the Department of Neonatology at the centre. Eti Kormbluth, MA, (Clin Social Work), is Senior Social Worker in the Department of Neonatology at the centre. Ofer Lavie, MD, is a Resident in the Department of Obstetrics and Gynaecology at the centre. Pnina Zadka, MS, is Senior
Epidemiologist in the Health Division of the Israel Central Bureau of Statistics, Ferusalem, Israel. Yeshayahu Aboulafia, MD, is a Senior Obstetrician in the Department of Obstetrics and Gynaecology at the Shaare Zedek Medical Centre and Arthur I Eidelman, $M D$, is the Director of the Department of Neonatology at the centre.

\section{References}

1 Committee on Bioethics, American Academy of Pediatrics. Guidelines on forgoing life-sustaining medical treatment. Pediatrics 1994; 93: 532-6.

2 Harlap S, Davies AM, Grover NB, Prywes R. The Jerusalem perinatal study: the first decade 1964-1973. Israel fournal of Medical Science 1977; 13: 1073-1 109.

3 Statistical abstracts of Israel. Central Bureau of Statistics 1994; $45: 144$.

4 Rostain AL, Bhutani VK. Ethical dilemmas of neonatal-perinatal surgery. Clinics in Perinatology 1989; 16: 275-302.

5 Segal S. Ethical issues presented by children with congenital anomalies. Seminars in Perinatology 1992; 16: 369-372.

6 Byrne P, Tyebkhan J, Laing LM. Ethical decisionmaking and neonatal resuscitation. Seminars in Perinatology 1994; 18: 36-41.

7 Todres ID, Guillemin J, Grodin M, Batten D. Lifesaving therapy for newborns: a questionnaire survey in the state of Massachussetts. Pediatrics 1988; 81: 643-649.

8 Steinberg A. Meningomyelocele in the neonate: medical and ethical considerations. Fournal of Perinatology 1991; 11: 51-56.

9 Jakobovits I. Jewish medical ethics - a brief overview. fournal of Medical Ethics 1983; 9: 109-112.

10 Eidelman AI. Caring for newborns: in Israel families look to two messengers of God. Hastings Center Report 1986; 16: 18-9.

11 Sabatello EF. Fertility patterns of the new immigrants to Israel: continuity or change? In: Schmeltz UO et al, eds. Papers in fewish demography. Jerusalem: Hebrew University, 1983: 305-314.

\section{News and notes}

\section{Annual Intensive Course on Medical Ethics}

The Annual Intensive Course on Medical Ethics will be held from 15-19 September, 1997 at Imperial College, London. It provides a stimulating multidisciplinary introduction to philosophical medical ethics for medical and nursing teachers, members of ethics committees, GPs, hospital consultants and health administrators. The course is organised in collaboration with the Institute of Medical Ethics.
Lectures/seminars, small and large groups will be led by leading international authorities in the field of medical ethics.

PGEA and CME accreditation sought.

For further information contact: Sally Verkaik, Imperial College Continuing Education Centre, London SW7 2AZ. Tel: (+44)171 594 6882/1. Fax: (+44)171594 6883. E-mail: cpd@ic.ac.uk 